\title{
PEMODELAN DAN ANALISIS KESTABILAN DINAMIKA KORUPSI POLITISI DALAM MASYARAKAT DEMOKRATIS
}

\author{
SETIA WAHYUNI, MAHDHIVAN SYAFWAN, BUDI RUDIANTO \\ Program Studi S1 Matematika, \\ Fakultas Matematika dan Ilmu Pengetahuan Alam, Universitas Andalas, \\ Kampus UNAND Limau Manis Padang, Indonesia. \\ email : setiawahyuni44@gmail.com
}

Diterima 9 Maret 2019 Direvisi 7 April 2019 Dipublikasikan 7 Mei 2019

\begin{abstract}
Abstrak. Penelitian ini membahas kembali penurunan model dinamika korupsi politisi dalam masyarakat demokratis. Model tersebut dikonstruksi dalam tinjauan politikekonomi, dengan variabel keadaan meliputi popularitas, aset tersembunyi, dan upaya penyelidikan kasus korupsi. Berdasarkan ada atau tidaknya upaya penyelidikan, model dibagi atas dua bagian, yaitu sistem korup dan sistem tak-korup. Dari analisis kestabilan terhadap sistem korup diperoleh tiga titik kesetimbangan yang stabil dan dari analisis kestabilan sistem tak-korup diperoleh dua titik kesetimbangan yang stabil.
\end{abstract}

Kata Kunci: Korupsi, Titik kesetimbangan, Analisis kestabilan

\section{Pendahuluan}

Korupsi merupakan suatu fenomena sosial yang sering terjadi dalam proses politik yang dianggap menyimpang dan merugikan masyarakat dan negara. Korupsi tampaknya telah menjadi tradisi yang panjang dalam proses politik, yang mana korupsi terjadi secara berulang-ulang, meskipun yang lama terberantas namun politisi yang baru bukan tidak mungkin terlibat dalam kasus korupsi.

Istilah demokrasi berasal dari bahasa Yunani, yaitu berasal dari kata democratos yang merupakan gabungan dari kata demos yang artinya "rakyat" dan cratos yang artinya "kekuasaan atau kedaulatan". Dengan demikian, demokrasi adalah kedaulatan rakyat. Adapun kedaulatan rakyat yang dimaksud dalam kehidupan bernegara adalah penyelenggaraan sistem pemerintahan yang dilaksanakan bersama rakyat. Dengan demikian negara yang menganut sistem demokrasi, kekuasaan pemerintahannya terbatas dan pemerintah tidak dapat bertindak sewenang-wenang kepada rakyatnya [2].

Secara normalnya hubungan demokrasi dengan korupsi dikaitkan dengan aksioma yang populer dari Prof. Lord Acton yang menegaskan: "Power tends to corrupt, absolute power corrupt absolutely" (kekuasaan cenderung korup, dan kekuasaaan yang absolut maka korupsinya juga absolut). Aksioma ini mengandung 
makna bahwa absolutisme pada dasarnya berbanding terbalik dengan korupsi. Dengan demikian berarti, jika suatu pemerintahan dijalankan dengan sistem demokrasi maka angka korupsi akan lebih rendah, begitu sebaliknya jika dijalankan secara absolut (otoriter), maka angka korupsi di negara tersebut akan meningkat [2].

Dalam makalah ini, dinamika korupsi politisi dalam masyarakat demokratis dijelaskan kembali penurunannya berdasarkan kajian yang dipaparkan oleh Sergio Rinaldi dkk (1998) [1]. Selanjutnya dilakukan analisis kestabilan terhadap model tersebut.

\section{Landasan Teori}

Pandang sistem persamaan diferensial berikut.

$$
\dot{\mathbf{x}}=\mathbf{f}(\mathbf{x})
$$

Definisi 2.1. [6] Titik kesetimbangan (disebut juga titik tetap, titik kritis atau titik stasioner) dari sistem (2.1) adalah solusi yang memenuhi persamaan

$$
\dot{\mathbf{x}}=\mathbf{f}(\mathbf{x})=\mathbf{0} \text {. }
$$

Definisi 2.2. [6] Titik kesetimbangan $\mathbf{x}^{*} \in \mathbb{R}^{n}$ dari sistem (2.1) dikatakan

(1) Stabil asimtotik jika titik kesetimbangan $\mathbf{x}^{*} \in \mathbb{R}^{n}$ stabil dan terdapat $\delta_{0}>0$ sedemikian sehingga untuk setiap solusi $\mathbf{x}(t)$ yang memenuhi $\left\|\mathbf{x}\left(t_{0}\right)-\mathbf{x}^{*}\right\|<\delta_{0}$ berlaku $\lim _{t \rightarrow \infty} \mathbf{x}(t)=\mathbf{x}^{*}$.

(2) Stabil jika untuk setiap $\epsilon>0$ terdapat $\delta>0$ sedemikian sehingga untuk setiap solusi $\mathbf{x}(t)$ yang memenuhi $\left\|\mathbf{x}\left(t_{0}\right)-\mathbf{x}^{*}\right\|<\delta$ berlaku $\left\|\mathbf{x}(t)-\mathbf{x}^{*}\right\|<\epsilon$ untuk $t \geq t_{0}$,

Definisi 2.2 menjelaskan bahwa kestabilan dari titik kesetimbangan dapat diketahui dari solusi persamaan diferensialnya. Namun, tidak semua persamaan diferensial dapat ditentukan dengan mudah solusi eksaknya. Dalam hal ini, metode pelinieran dapat digunakan untuk menentukan apakah titik kesetimbangan tersebut bersifat stabil atau tidak di sekitar titik kesetimbangan.

Sistem (2.1) di sekitar titik kesetimbangan $\mathbf{x}^{*}$ dapat didekati oleh sistem linier

$$
\dot{\mathbf{y}}=J \mathbf{y}
$$

dimana $\mathbf{y}=\left[x_{1}-x^{*}, x_{2}-x^{*}, \cdots, x_{n}-x^{*}\right]^{T}$ dan

$$
J \equiv J\left(\mathbf{x}^{*}\right)=\left(\begin{array}{cccc}
\frac{\partial f_{1}\left(\mathbf{x}^{*}\right)}{\partial x_{1}} & \frac{\partial f_{1}\left(\mathbf{x}^{*}\right)}{\partial x_{2}} & \cdots & \frac{\partial f_{1}\left(\mathbf{x}^{*}\right)}{\partial x_{n}} \\
\frac{\partial f_{2}\left(\mathbf{x}^{*}\right)}{\partial x_{1}} & \frac{\partial f_{2}\left(\mathbf{x}^{*}\right)}{\partial x_{2}} & \cdots & \frac{\partial f_{2}\left(\mathbf{x}^{*}\right)}{\partial x_{n}} \\
\vdots & \vdots & \ddots & \vdots \\
\frac{\partial f_{n}\left(\mathbf{x}^{*}\right)}{\partial x_{1}} & \frac{\partial f_{n}\left(\mathbf{x}^{*}\right)}{\partial x_{2}} & \cdots & \frac{\partial f_{n}\left(\mathbf{x}^{*}\right)}{\partial x_{n}}
\end{array}\right)
$$

Matriks $J$ disebut matriks Jacobian dari sistem (2.1) yang dihitung di titik kesetimbangan $\mathbf{x}^{*}$.

Karena sistem (2.2) linier orde satu, maka solusinya dapat ditulis dalam bentuk

$$
\mathbf{y}=\mathbf{p} e^{\lambda t}
$$


dimana $\lambda$ adalah suatu skalar dan $\mathbf{p}$ adalah suatu vektor konstan tak nol. Dengan mensubstitusi y ke dalam sistem (2.2), diperoleh

$$
(J-\lambda I) \mathbf{p}=\mathbf{0} .
$$

Persamaan (2.3) menyatakan bahwa $\lambda$ adalah nilai eigen dari matriks $J$ dan $\mathbf{p}$ adalah vektor eigen yang bersesuaian dengan nilai eigen $\lambda$. Oleh karena itu, kestabilan sistem (2.2) di sekitar titik kesetimbangan ditentukan oleh nilai-nilai eigen dari matriks Jacobiannya, yang diberikan oleh teorema berikut.

Teorema 2.3. [8] Pandang sistem (2.1) dimana matriks Jacobian $J$ mempunyai $k$ nilai eigen yang berbeda, misalkan $\lambda_{1}, \lambda_{2}, \cdots, \lambda_{k}$, dengan $k \leq n$. Titik kesetimbangan $\mathbf{x}^{*}$ dikatakan stabil jika dan hanya jika bagian riil dari semua nilai eigennya bernilai non-positif, yaitu $\operatorname{Re}\left(\lambda_{i}\right) \leq 0$ untuk setiap $i=1,2, \cdots, k$.

\section{Konstruksi Model}

Model dinamika korupsi merupakan sistem dinamik yang terdiri dari tiga variabel keadaan, yaitu:

(a) $x(t)$, yaitu dukungan publik (popularitas) terhadap politisi pada waktu $t$,

(b) $y(t)$, yaitu aset (tersembunyi) yang dimiliki politisi pada waktu $t$,

(c) $z(t)$, yaitu upaya penyelidikan kasus korupsi pada waktu $t$ (yaitu, sejumlah tindakan yang dilakukan oleh polisi, pengadilan, dan pers yang bertujuan untuk mengungkap korupsi).

Variabel-variabel di atas diukur dengan menggunakan satuan yang berbeda. Sebagai contoh, $x$ dapat berupa persentase masyarakat yang memiliki penilaian positif terhadap politisi, $y$ dapat berupa nilai moneter dari aset yang terkumpul oleh politisi melalui praktek-praktek ilegal, dan $z$ dapat berupa banyaknya petugas yang terlibat dalam penyelidikan kasus korupsi yang dilakukan oleh politisi.

Selain itu juga dipertimbangkan beberapa hal berikut ini:

(1) Tindakan positif yang dilakukan politisi sebagai fungsi terhadap popularitas, dinyatakan dengan $A(x)$. Perubahan popularitas bergantung pada inovasi politisi, yaitu seberapa jauh tindakan politisi melebihi atau jatuh di bawah harapan publik. Dengan kata lain, peningkatan popularitas politisi bergantung kepada tindakan positif politisi tersebut. Diasumsikan bahwa $A^{\prime}(x)>0$ artinya jika semakin popular politisi maka tindakannya akan semakin besar.

(2) Harapan publik terhadap tindakan politisi sebagai fungsi terhadap popularitas, dinyatakan dengan $E(x)$. Jelas bahwa harapan publik terhadap tindakan seorang politisi meni-ngkat seiring dengan meningkatnya popularitas dari politisi tersebut. Dengan demikian berlaku $E^{\prime}(x)>0$.

(3) Laju suap yang didefinisikan sebagai total aliran uang yang diperoleh politisi dari praktek-praktek ilegal sebagai fungsi terhadap popularitas dan upaya penyelidikan, dinyatakan sebagai $B(x, y)$. Sangat beralasan untuk mengatakan bahwa semakin populer seorang politisi, maka akan semakin terbuka kesempatan menyalahgunakan kekuasaan mereka untuk kepentingan pribadi (yaitu, 
mereka menuntut suap yang lebih besar karena mereka dapat mengamankan 'keuntungan' yang lebih tinggi untuk pihak yang menyuap). Dengan demikian dapat diasumsikan bahwa $B_{x}>0$.

(4) Konsumsi pribadi politisi yang bergantung pada laju suap $B$ dan aset $y$, dinotasikan dengan $C(B, y)$. Sangat beralasan untuk mengasumsikan bahwa semakin meningkat laju suap dan aset yang dimiliki seorang politisi, maka akan semakin meningkatkan pula konsumsi pribadi politisi tersebut (yaitu $C_{B}>0$ dan $\left.C_{y}>0\right)$.

(5) Penyingkapan kasus korupsi, dinotasikan dengan $D$. Dalam hal ini $D$ dapat diukur dari jumlah aset yang disita oleh polisi dan pengadilan. Oleh karena itu sangat beralasan untuk mengasumsikan bahwa $D$ dipengaruhi oleh aset $y$ dan upaya penyelidikan $z$, yaitu $D=D(y, z)$. Turunan parsial $D_{y}>0$ menjelaskan bahwa penyingkapan kasus korupsi meningkat seiring dengan bertambahnya aset (tersembunyi). Selanjutnya $D_{z}>0$ mengandung makna bahwa penyingkapan kasus korupsi meningkat ketika pengadilan, polisi, dan pers memperluas upaya-upaya penyelidikan mereka.

Berdasarkan penjelasan dan asumsi-asumsi di atas maka model laju perubahan masing-masing variabel keadaan sebagai berikut:

(1) Laju perubahan popularitas dinyatakan oleh persamaan diferensial berikut:

$$
\dot{x}=\mu^{+}(A(x)-E(x))-\mu^{-} x D(y, z),
$$

dimana $\mu^{+}$dan $\mu^{-}$masing-masing mengidentifikasi reaksi publik terhadap inovasi politisi (selisih antara tindakan positif dan harapan publik) dan penyingkapan kasus korupsi.

(2) Laju perubahan aset dinyatakan oleh persamaan diferensial berikut:

$$
\dot{y}=r y+B(x, y)-C(B(x, y), y)-D(y, z),
$$

dimana $r$ mengidentifikasi tingkat suku bunga di Bank.

(3) Laju perubahan upaya penyelidikan kasus korupsi dinyatakan oleh persamaan diferensial berikut:

$$
\dot{z}=\sigma D(y, z)-\delta z
$$

dimana $\sigma$ menyatakan tingkat independensi dari penyidik. Asumsi ini sangat penting dalam sistem demokratis. Tanpa asumsi ini, kasus korupsi akan menyebar dan mungkin masih banyak yang belum terungkap, atau bisa juga ditangani secara diskriminatif dan $\delta$ menyatakan ukuran besarnya kegigihan dalam mengungkap kasus korupsi.

Untuk mempermudah dalam menganalisis model, digunakan fungsi-fungsi berikut 
140 Setia Wahyuni dkk.

yang bersesuaian dengan asumsi yang telah ditetapkan, yaitu

$$
\begin{aligned}
A(x) & =\frac{\alpha x}{\beta+x}, \\
E(x) & =k x, \\
B(x, y) & =\phi x y, \\
C(B, y) & =\omega B(x, y)+\theta y, \\
D(y, z) & =\gamma y z .
\end{aligned}
$$

Semua parameter yang digunakan dalam persamaan (3.4) - (3.8) bernilai positif bergantung pada karakteristik individu dan negara masing-masing. Berdasarkan fungsi-fungsi yang telah ditetapkan pada persamaan (3.4) - (3.8) dan kemudian disubstitusi ke persamaan $(3.1)-(3.3)$, maka diperoleh

$$
\begin{aligned}
& \dot{x}=\mu^{+}[\alpha /(\beta+x)-k] x-\mu^{-} \gamma x y z, \\
& \dot{y}=\varepsilon x y-\gamma y z-\rho y, \\
& \dot{z}=\sigma \gamma y z-\delta z .
\end{aligned}
$$

dimana

$$
\begin{aligned}
& \rho=\theta-r, \\
& \varepsilon=(1-\omega) \phi .
\end{aligned}
$$

Karena diasumsikan polisi, pengadilan dan pers memiliki independensi (berlaku pada masyarakat demokratis), maka ada/tidak adanya upaya penyelidikan mengindikasikan ada/tidak adanya kasus korupsi.

Dengan demikian sistem (3.9) dikatakan sistem korup jika $z \neq 0$ (ada penyelidikan) dan dikatakan sistem tak-korup jika $z=0$ (tidak ada penyelidikan). Oleh karena itu persamaan untuk sistem tak-korup adalah

$$
\begin{aligned}
& \dot{x}=\mu^{+}[\alpha /(\beta+x)-k] x, \\
& \dot{y}=\varepsilon x y-\rho y .
\end{aligned}
$$

Semua nilai-nilai parameter diasumsikan bernilai positif.

\section{Analisis Kestabilan Model}

\subsection{Analisis Kestabilan Sistem Korup}

Titik kesetimbangan dari sistem (3.9) dapat ditentukan dengan menetapkan variabel-variabel tak bebas sebagai fungsi konstan, yaitu $\dot{x}=0, \dot{y}=0, \dot{z}=0$.

Titik kesetimbangan yang diperoleh adalah

$$
\begin{aligned}
& E_{1}(x, y, z)=(0,0,0), \\
& E_{2}(x, y, z)=\left(0, \frac{\delta}{\sigma \gamma}, \frac{-\rho}{\gamma}\right), \\
& E_{3}(x, y, z)=\left(x^{*}, 0,0\right), \text { dimana } x^{*}=\frac{\alpha-k \beta}{k} .
\end{aligned}
$$


Matriks Jacobian dari sistem korup adalah

$$
J(x, y, z)=\left(\begin{array}{ccc}
\mu^{+}\left(\frac{\alpha \beta}{(\beta+x)^{2}}-k\right)-\mu^{-} \gamma y z & -\mu^{-} \gamma x z & -\mu^{-} \gamma x y \\
\varepsilon y & \varepsilon x-\gamma z-\rho & -\gamma y \\
0 & \gamma \sigma z & \gamma \sigma y-\delta
\end{array}\right)
$$

Pada titik kesetimbangan yang pertama $E_{1}(0,0,0)$ diperoleh hasil substitusi ke matriks Jacobian (4.1) sebagai berikut.

$$
J(x, y, z)=\left(\begin{array}{ccc}
\mu^{+}\left(\frac{\alpha}{\beta}-k\right) & 0 & 0 \\
0 & -\rho & 0 \\
0 & 0 & -\delta
\end{array}\right) .
$$

Akar-akar persamaan karakteristik yang diperoleh adalah:

$$
\begin{aligned}
& \lambda_{1}=\mu^{+}\left(\frac{\alpha}{\beta}-k\right), \\
& \lambda_{2}=-\rho \text { dan } \lambda_{3}=-\delta .
\end{aligned}
$$

Selanjutnya kriteria kestabilan untuk titik kesetimbangan $E_{1}$ diberikan dalam teorema berikut.

Teorema 4.1. Misalkan $\mu^{+}, \alpha, \beta, \rho, \delta$ adalah parameter positif. Jika $\frac{\alpha}{\beta}<k$, maka titik kesetimbangan $E_{1}=(0,0,0)$ dari sistem (3.9) stabil.

Pada titik kesetimbangan yang kedua $E_{2}\left(0, \frac{\delta}{\sigma \gamma}, \frac{-\rho}{\gamma}\right)$ diperoleh hasil substitusi ke matriks Jacobian (4.1) sebagai berikut.

$$
J(x, y, z)=\left(\begin{array}{ccc}
\mu^{+}\left(\frac{\alpha}{\beta}-k\right)+\mu^{-\frac{\delta \rho}{\sigma \gamma}} & 0 & 0 \\
\frac{\varepsilon \delta}{\sigma \gamma} & 0 & -\frac{\delta}{\sigma} \\
0 & \rho \sigma & 0 \\
\cdot & &
\end{array}\right)
$$

Akar-akar persamaan karakteristik yang diperoleh adalah:

$$
\begin{aligned}
& \lambda_{1}=\sqrt{-\delta \rho} \\
& \lambda_{2}=-\sqrt{-\delta \rho} \\
& \lambda_{3}=\mu^{+}\left(\frac{\alpha}{\beta}-k\right)+\mu^{-} \frac{\delta \rho}{\gamma \sigma} .
\end{aligned}
$$

Selanjutnya kriteria kestabilan untuk titik kesetimbangan $E_{2}$ diberikan dalam teorema berikut.

Teorema 4.2. Misalkan $\mu^{+}, \mu^{-}, \alpha, \beta, \rho, \delta, \gamma, \sigma, k$ adalah parameter positif. Jika $\left(\mu^{+}\left(\frac{\alpha}{\beta}\right)+\mu^{-}\left(\frac{\delta \rho}{\gamma \sigma}\right)\right)<\mu^{+} k$, maka titik kesetimbanganE $E_{2}\left(0, \frac{\delta}{\sigma \gamma}, \frac{-\rho}{\gamma}\right)$ dari sistem (3.9) stabil.

Pada titik kesetimbangan yang ketiga $E_{3}\left(\frac{\alpha-k \beta}{k}, 0,0\right)$ diperoleh hasil substitusi ke matriks Jacobian (4.1) sebagai berikut:

$$
J(x, y, z)=\left(\begin{array}{ccc}
\mu^{+}\left(\frac{\alpha \beta}{\left(\beta+\frac{\alpha-k \beta}{k}\right)^{2}}-k\right) & 0 & 0 \\
0 & \varepsilon\left(\frac{\alpha-k \beta}{k}\right)-\rho & 0 \\
0 & 0 & -\delta
\end{array}\right) .
$$


Akar-akar karakteristik yang diperoleh adalah

$$
\begin{aligned}
& \lambda_{1}=\mu^{+}\left(\frac{k \beta}{\alpha}-1\right) k, \\
& \lambda_{2}=\varepsilon\left(\frac{\sigma-k \beta}{k}\right)-\rho, \\
& \lambda_{3}=-\delta
\end{aligned}
$$

Selanjutnya kriteria kestabilan untuk titik kesetimbangan $E_{3}$ diberikan dalam teorema berikut.

Teorema 4.3. Misalkan $\alpha, \beta, \rho, \delta$ adalah parameter positif. Jika $\frac{k \beta}{\alpha}<1$ dan $\frac{\varepsilon \sigma}{k}<$ $\varepsilon k \beta+\rho$, maka titik kesetimbangan $E_{3}\left(\frac{\alpha-k \beta}{k}, 0,0\right)$ dari sistem (3.9) stabil.

\subsection{Analisis Kestabilan Sistem Tak-Korup}

Titik kesetimbangan dari sistem (3.10) dapat ditentukan dengan menetapkan variabel-variabel tak bebas sebagai fungsi konstan, yaitu $\dot{x}=0, \dot{y}=0$.

Titik kesetimbangan yang diperoleh adalah

$$
\begin{aligned}
& R_{1}(x, y)=(0,0), \\
& R_{2}(x, y)=\left(\frac{\alpha-k \beta}{k}, 0\right) .
\end{aligned}
$$

Matriks Jacobian dari sistem tak-korup adalah

$$
J(x, y)=\left(\begin{array}{cc}
\mu^{+}\left(\frac{\alpha \beta}{(\beta+x)^{2}}-k\right) & 0 \\
\varepsilon y & \varepsilon x-\rho
\end{array}\right) .
$$

Pada titik kesetimbangan yang pertama $R_{1}(0,0)$ diperoleh hasil substitusi ke matriks Jacobian (4.2), yaitu

$$
J(x, y)=\left(\begin{array}{cc}
\mu^{+}\left(\frac{\alpha}{\beta}-k\right) & 0 \\
0 & -\rho
\end{array}\right) .
$$

Akar-akar persamaan karakteristik yang diperoleh adalah :

$$
\lambda_{1}=\mu^{+}\left(\frac{\alpha}{\beta}-k\right) \text { dan } \lambda_{2}=-\rho .
$$

Selanjutnya kriteria kestabilan untuk titik kesetimbangan $R_{1}$ diberikan dalam teorema berikut.

Teorema 4.4. Misalkan $\mu^{+}, \alpha, \beta, \rho, \delta$ adalah parameter positif. Jika $\frac{\alpha}{\beta}<k$, maka titik kesetimbangan $R_{1}=(0,0)$ dari sistem (3.10) stabil.

Pada titik kesetimbangan yang kedua $R_{2}\left(\frac{\alpha-k \beta}{k}, 0\right)$ diperoleh hasil substitusi ke matriks Jacobian (4.2), yaitu

$$
J(x, y)=\left(\begin{array}{cc}
\mu^{+}\left(\frac{\alpha \beta}{\left(\beta+\frac{\alpha-k \beta}{k}\right)^{2}}-k\right) & 0 \\
0 & \varepsilon\left(\frac{\alpha-k \beta}{k}\right)-\rho
\end{array}\right) .
$$

Akar-akar persamaan karakteristik yang diperoleh adalah

$$
\lambda_{1}=\mu^{+}\left(\frac{k \beta}{\alpha}-1\right) k, \text { dan } \lambda_{2}=\varepsilon\left(\frac{\sigma-k \beta}{k}\right)-\rho .
$$


Selanjutnya kriteria kestabilan untuk titik kesetimbangan $R_{2}$ diberikan dalam teorema berikut.

Teorema 4.5. Misalkan $\alpha, \beta, \rho, \delta$ adalah parameter positif. Jika $\frac{k \beta}{\alpha}<1$ dan $\frac{\varepsilon \sigma}{k}<$ $\varepsilon k \beta+\rho$, maka titik kesetimbangan $R_{2}\left(\frac{\alpha-k \beta}{k}, 0\right)$ dari sistem (3.10) stabil.

\section{Kesimpulan}

Model dinamika korupsi dalam masyarakat demokratis terbagi atas dua bagian yaitu sistem korup dan sistem tak-korup. Pada sistem korup terdapat empat titik kesetimbangan yaitu $E_{1}, E_{2}, E_{3}, E_{4}$ dan analisis modelnya dibatasi hanya untuk tiga titik kesetimbangan yang pertama. Dari analisis kestabilan diperoleh kriteria titik kesetimbangan sistem korup yang stabil. Pada sistem tak-korup terdapat dua titik kesetimbangan yaitu $R_{1}, R_{2}$. Dari analisis kestabilan diperoleh kriteria titik kesetimbangan sistem tak-korup yang stabil.

\section{Ucapan Terima kasih}

Terima kasih kepada Bapak Prof. Dr. Muhafzan, Bapak Dr. Ahmad Iqbal Baqi, dan Bapak Efendi, M.Si selaku penguji tugas akhir sehingga penelitian ini dapat disempurnakan dengan baik.

\section{Daftar Pustaka}

[1] Rinaldi, Sergio, Feichtinger, G and Wirl, F. 1998. Corruption Dynamics in Democratic Societies. Complexity 3(5): $53-64$

[2] https://www.academia.edu/35815028/Makalah-Demokrasi-dan-Korupsi, diakses tanggal 2 Januari 2019

[3] Finizio, J and Ladas, T. 1982. An Introduction to Differential Equations. Wadsworth Publishing Company Belmon, California

[4] Wazwaz, A. M. 2009. Partial Differential Equation and Solitary Waves Theory. Springer, Berlin

[5] Anton, H. 1991.Aljabar Linier Elementer Edisi Kedelapan Jilid 1. Erlangga, Jakarta

[6] Boyce, W. E dan Prime. 2001 Elementary Differential Equations and Boundary Value Problems. John Wiley Sons, New York

[7] Grossman, S.I. 1986.Multivariable Calculus, Linear Algebra, and Differential Equations. Second Edition. Academic Press, Orlando.

[8] G. J. Olsder. 1994. Mathematical System Theory. Delft University Press, Delft 